\title{
ERRATUM
}

\section{Involvement of Inferior Parietal Lobules in Prospective Memory Impairment During Acute MDMA (Ecstasy) Intoxication: An Event-Related fMRI Study}

Johannes G Ramaekers, KPC Kuypers, M Wingen, A Heinecke and E Formisano

Neuropsychopharmacology (2009) 34, I883- I884; doi:I0.1038/npp.2009.I8

Correction to: Neuropsychopharmacology advance online publication, 17 December 2008. doi:10.1038/npp.2008.219
In this article, corrections were made to Figures 1 and 2; the revised figures are shown below:
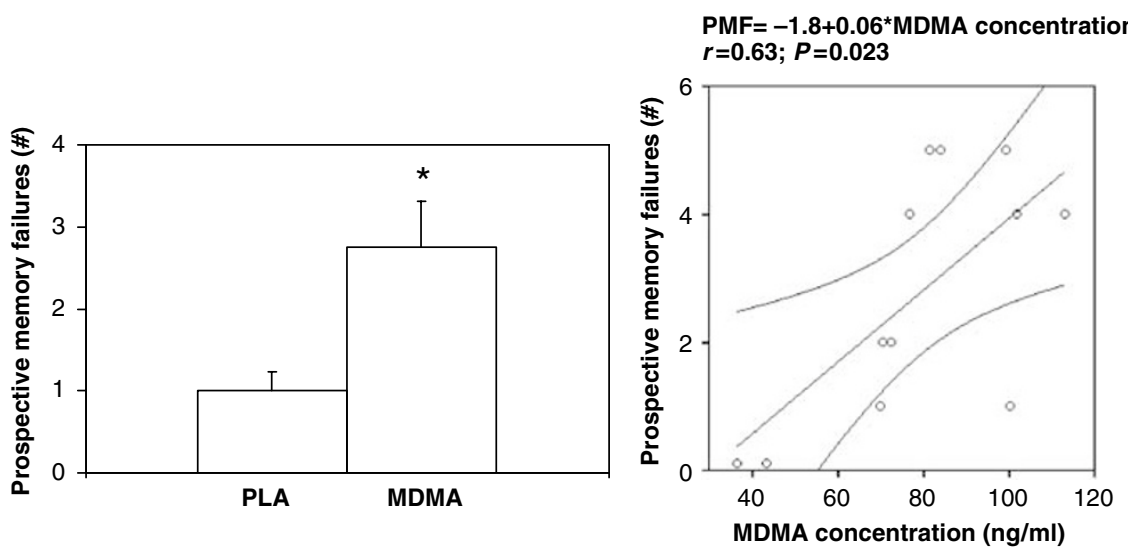

Figure I The left panel shows mean (SE) prospective memory failures after MDMA and placebo administration during No go trials. The right panel shows a linear regression $(95 \% \mathrm{Cl}$ ) between MDMA concentration and prospective memory failures in 12 subjects (PMF = prospective memory failures; $* 2<0.05)$. 
Left, thalamus, putamen
Right, inferior parietal lobule
Left, precuneus Parietal lobule
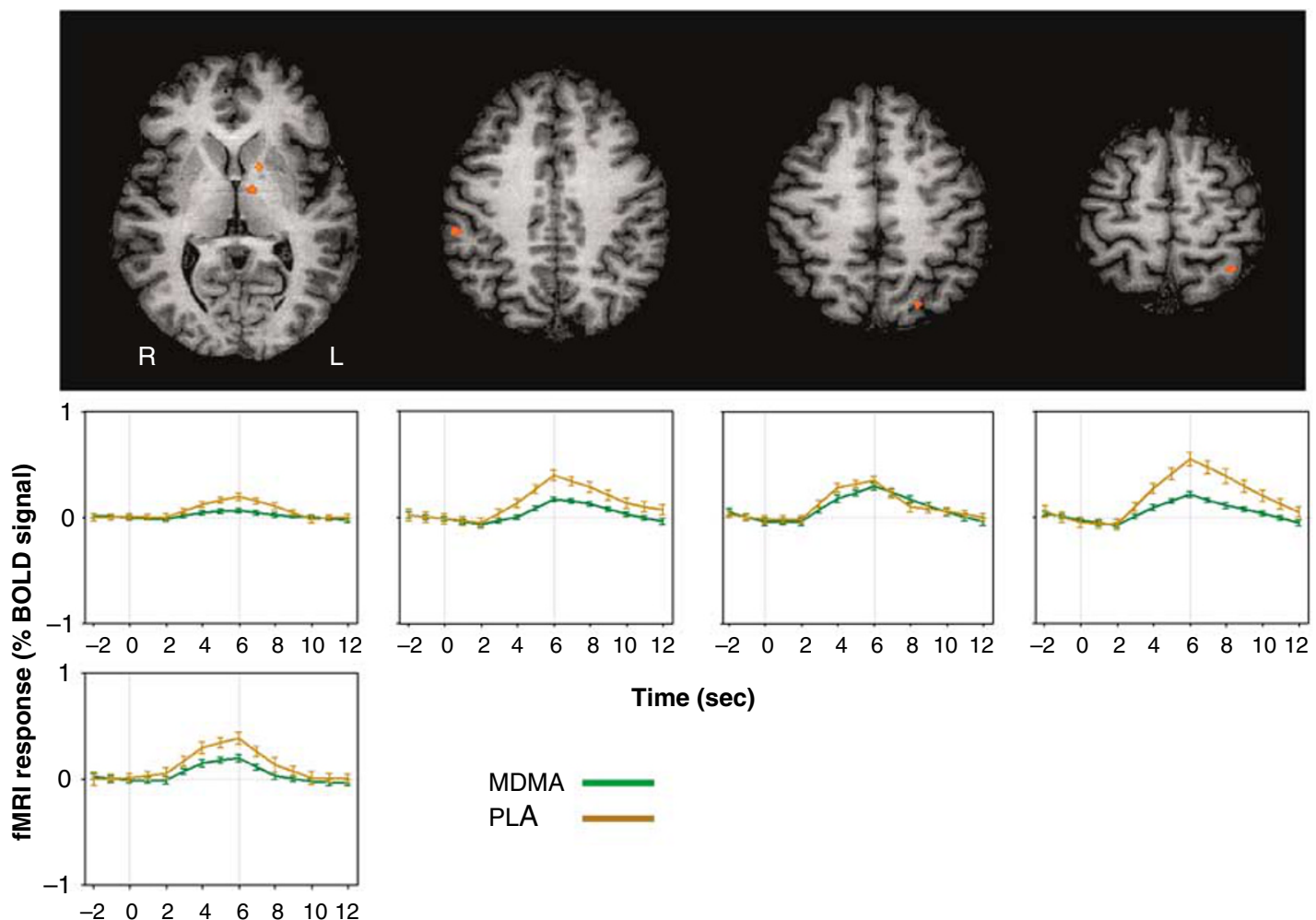

Time (sec)

MDMA

PLA

Figure 2 Transversal sections of the brain showing significant MDMA effects during Go trials in five brain areas. Event-related BOLD responses averaged over Go trials during MDMA and placebo are given in the lower panels for each brain area. 